\section{MS35-O2 Uptake and release of small molecules by flexible 1D coordination polymers that exhibit latent nanoporosity}

Lee Brammer ${ }^{1}$, Iñigo J. Vitórica-Yrezábal ${ }^{2}$, James S. Wright ${ }^{1}$

1. Department of Chemistry, University of Sheffield, Sheffield S3 $7 \mathrm{HF}, \mathrm{UK}$

2. School of Chemistry, University of Manchester, Oxford Road, Manchester, M13 9PL, UK

email: lee.brammer@sheffield.ac.uk

Families of 1D coordination polymers have been developed in which flexibility of the polymer, arising from side-chain conformational changes and bond-breaking and reformation at labile metal centres, enables the uptake and release of a variety of small molecules by these materials in their crystalline form. ${ }^{[1-4]}$ These crystalline materials are not formally porous, but their flexibility results in latent porosity that facilitates the uptake and release processes. Transformations have been followed extensively by in situ diffraction studies, in some cases as single crystal-to-single crystal processes, but always also by XRPD. Diffraction studies are supported by TGA/DSC studies and use of gas-phase IR spectroscopy to establish equilibrium gas-solid behaviour where guest molecules are released into the vapour phase. The presentation will focus on using diffraction in combination with other techniques to investigate mechanism, and will provide examples that illustrate selectivity of guest entrapment.

[1] S. Libri, M. Mahler, G. Mínguez Espallargas, D. C. N. G. Singh, J. Soleimmanejad, H. Adams, M. D. Burgard, N. P. Rath, M. Brunelli, L. Brammer, Angew. Chem. Int. Ed. 2008, 47, 1693-1697.

[2] I. J. Vitórica-Yrezábal, G. Mínguez Espallargas, J. Soleimannejad, A. J. Florence, A. J. Fletcher, L. Brammer, Chem. Sci. 2013, 4, 696-708.

[3] J. S. Wright, I. J. Vitórica-Yrezábal, H. Adams, S. P. Thompson, A. H. Hill, L. Brammer, IUCrJ 2015, 2, 188-197.

[4] I. J. Vitórica-Yrezábal, S. Libri, J. R. Loader, G. Mínguez Espallargas, M. Hippler, A. J. Fletcher, S. P. Thompson, J. E. Warren, D. Musumeci, M. D. Ward, L. Brammer, Chem. Eur. J. 2015, in press.

Keywords: Flexible coordination polymer, molecular entrapment, latent porosity, guest uptake, guest release, in situ diffraction

\section{MS35-O3 Coordination metallacycles assembled into microporous materials \\ Luciano Marchio' ${ }^{1}$, Irene Bassanetti ${ }^{1}$, Corrado Atzeri ${ }^{1}$, Matteo Tegoni ${ }^{1}$, Vincent L. Pecoraro ${ }^{2}$}

1. Dipartimento di Chimica, Universita' degli Studi di Parma, Parma, Italy

2. Department of Chemistry, University of Michigan, Ann Arbor, MI, USA

email:marchio@unipr.it

Porous solid materials represent one of the most intense areas of study for chemists, physicists, and materials scientists [1]. These systems have found a large number of applications in many fields, such as adsorption, separation and purification, as well as catalysis [2]. The construction of a reticular and porous architecture highly depends on the building units linked by means of different types of interactions. In particular, within the class of materials comprising covalent interactions the most notable examples are represented by covalent organic frameworks (COF) and porous aromatic frameworks (PAF). In the large and continuously growing class of metal organic framework (MOF) the main source of structural variability derives by the optimal match between an organic ligand bound to a metal center. Porous materials can also be obtained by the connections of oligomeric units by means of supramolecular interactions [1]. In the present contribution we show how two different oligomeric metallacycles, namely silver(I) hexamers [3] and copper (II) metallacrowns [4], can generate stable porous crystals. The role of the counteranion $\left(\mathrm{BF}_{4}^{-}, \mathrm{PF}_{6}^{-}, \mathrm{NO}_{3}^{-}, \mathrm{CF}_{3} \mathrm{SO}_{3}^{-}, \mathrm{CH}_{3} \mathrm{CO}_{2}^{-}\right)$is of fundamental importance in defining the supramolecular interactions responsible in the way the metallacycles self-assembled into a diversity of 3D supramolecular architectures and cavities. The structural features and gas sorption properties will be presented.

[ [1] T. R. Cook, Y. R. Zheng, P. J. Stang Chem. Rev., 2013, 113, 734-777. [2] C. Janiak, J. K. Vieth New J. Chem. 2010, 34, 2366-2388. [3] I. Bassanetti, A. Comotti, P. Sozzani, S. Bracco, G. Calestani, F. Mezzadri, L. Marchiò J. Am. Chem. Soc., 2014, 136, 14883-14895. [4] G. Mezei, C. M. Zaleski, V. L. Pecoraro Chem. Rev., 2007, 107, 4933-5003.
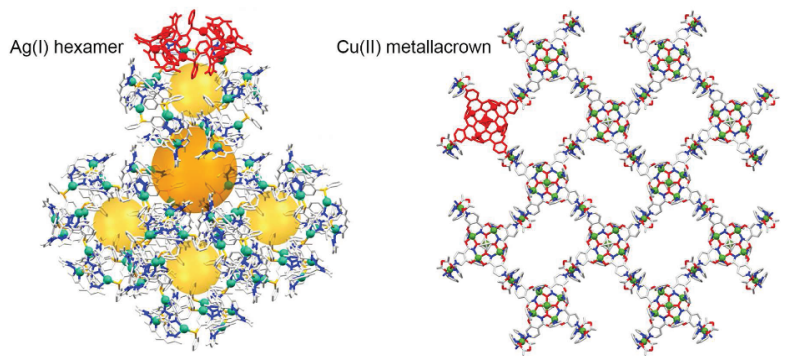

Figure 1. Crystal packing of the $\mathrm{Ag}(\mathrm{I})$ hexamers and of the $\mathrm{Cu}(\mathrm{II})$ metallacrown. In red are highlighted the building units.

Keywords: coordination polymers, metallacrowns, microporosity 